\title{
Gold determination in soil by ICP-MS: comparison of sample pretreatment methods
}

\author{
Xiaodan Tang, Bing Li, Jilong Lu, Hongyan Liu and Yuyan Zhao* (D)
}

\begin{abstract}
At present, the direct gold determination in geological samples by inductively coupled plasma mass spectrometry (ICP-MS) is still an arduous challenge due to both spectral and background interferences. It is very important and necessary to study the pretreatment processes; therefore, the polyurethane foam treatment and sample digestion methods are explored and compared here. The experimental results showed that the gold adsorption rate of treated foam was significantly improved as the impurities in the foam were cleaned up, and the potential difference of the liquid membrane was increased. Meanwhile, the combination of the foam enrichment and thiourea desorption achieved the selective adsorption and desorption of gold ions, eliminated the interference of coexisting ions, and perfected the detection limits. Compared with the traditional electric heating plate digestion method, microwave digestion, a closed digestion method, had the advantages of less sample and reagent dosage, short time consumption, high degree of automation, thorough digestion, good security, and environmental friendliness and met the requirements of green chemistry development. The proposed microwave digestion-foam enrichment-thiourea desorption-ICP-MS determination method was applied to the gold test in soil samples of the actual gold mining area. It has the great potential as a routine laboratory procedure.
\end{abstract}

Keywords: Gold, Digestion, Foam enrichment, Desorption, Inductively coupled plasma mass spectrometry

\section{Introduction}

Gold $(\mathrm{Au})$ is an extraordinary precious metal that is widely used in many fields (Danscher and Larsen 2010; Pyrzynska 2012; Sheoran et al. 2013; Yang and Hashmi 2014; Wang et al. 2015; Noel 2016; Maduraiveeran and Ramaraj 2017; Alim et al. 2018; Yeo et al. 2018), such as petrochemicals, aerospace, information technology, electronics, metallurgy, electrical, nuclear power, jewelry, and medicine. Rapid, sensitive, and accurate Au determination is a long-term concern in geosciences, mining industries, analytical chemistry, and spectroscopy. However, Au has low concentrations in most geological samples; its separation and enrichment are harder than

\footnotetext{
* Correspondence: zhaoyuyan@jlu.edu.cn

College of Geo-exploration Science and Technology, Jilin University, Changchun 130026, China
}

\section{Springer Open}

other metal elements. Therefore, the Au analysis has always been difficult.

Until now, the widely used Au test methods include titration (Stefano et al. 2015), atomic absorption spectrometry (Yilmaz and Soylak 2014; Choi et al. 2017; Zhou et al. 2017; Tang et al. 2019), inductively coupled plasma optical emission spectroscopy (George and Konstantinos 2016; Hassan et al. 2016; Xue et al. 2016), microwave plasma atomic emission spectrometry (Balaram et al. 2013), and inductively coupled plasma mass spectrometry (ICP-MS) (Liu et al. 2013; Tao et al. 2017; Satyanarayanan et al. 2018; Chen et al. 2019). Among them, ICP-MS meets the test conditions of most geological samples and has the advantages of low detection limit, high sensitivity, and wide linear range (Qi et al. 2011; Resano et al. 2012; Yim et al. 2012; Strnad

(c) The Author(s). 2020 Open Access This article is licensed under a Creative Commons Attribution 4.0 International License, which permits use, sharing, adaptation, distribution and reproduction in any medium or format, as long as you give appropriate credit to the original author(s) and the source, provide a link to the Creative Commons licence, and indicate if changes were made. The images or other third party material in this article are included in the article's Creative Commons licence, unless indicated otherwise in a credit line to the material. If material is not included in the article's Creative Commons licence and your intended use is not permitted by statutory regulation or exceeds the permitted use, you will need to obtain permission directly from the copyright holder. To view a copy of this licence, visit http://creativecommons.org/licenses/by/4.0/. 
et al. 2016; Berezhnaya and Dubinin 2017). Hence, ICPMS was used here to determine the Au content.

Unfortunately, the direct determination of micro/trace $\mathrm{Au}$ in geological samples by ICP-MS is still a daunting challenge, which is subject to both spectral and background interferences. These interferences from sample and instrument together lead to the problems of isotope interference, matrix effect, low ionization rate, memory effect, and so on during the Au determination. To solve them, different pretreatment methods such as the removal of isotope interference, the addition of plasma modifier, the elimination of memory effect, the enrichment and separation of gold from the matrix samples have been continuously studied and reported. In 2015, Guo's group (Guo et al. 2015) proposed a potential method for trace Au test in geological samples without preconcentration procedures. This method combined the ion-molecule reaction ICP-MS and methane plasma modifier technique, thereby reduced the interference of ${ }^{181} \mathrm{Ta}^{16} \mathrm{O}^{+}$and ${ }^{180} \mathrm{Hf}^{16} \mathrm{OH}^{+}$on ${ }^{197} \mathrm{Au}$ by three orders of magnitude, decreased the background signal to $50 \%$, and increased the $\mathrm{Au}$ sensitivity by 4 times. Then, the method was improved by Ar aerosol dilution ICP-MS after aqua regia extraction in 2017 (Tao et al. 2017). The background signal originating from the interfering residual oxide and/or hydroxides ions was further reduced by up to $60 \%$. Wang and Brindle discovered that the addition of L-cysteine in the sample matrix could prevent the gold memory effect in ICP-MS, and the use of ColdBlock $^{\text {mix }}$ digester and nitric acid-hydrobromic acid might recover gold efficiently from the geological samples (Wang and Brindle 2014). In addition to the improvement of the direct method, the enrichment and separation in the indirect method are also worth studying and often necessary for measuring Au content sensitively and accurately. According to the literature survey, many methods, including coprecipitation (Itagaki et al. 2000), ion exchange (Al-Merey et al. 2003), extraction (De La Calle et al. 2011; Hassan et al. 2011; Oya et al. 2014), and adsorption ( $\mathrm{Qu}$ et al. 2008; Bashammakh et al. 2009; Qu et al. 2009; Afzali et al. 2010), have been applied for the $\mathrm{Au}$ separation from various matrices. Among them, adsorption is one of the most effective separation techniques due to its merits of high preconcentration factor, simple operation, time saving, excellent selectivity, and the ability to cooperate with different detection techniques. It should be noted that the cost, operability, and efficiency of the adsorption method largely depend on the selection of sorbent materials. However, commonly used sorbents such as silica gel (Sabermahani et al. 2016), resin (Xu et al. 2019), activated carbon ( $\mathrm{Tu}$ et al. 2011), carbon nanotubes (Liang et al. 2008), and magnetic nanoparticles (Ilankoon et al. 2020) are expensive and/or harmful to the environment. Hence, this article chose the polyurethane foam (PUF) with the advantages of high efficiency, low cost, easy handling, and convenient storage to adsorb Au.

Commercially available PUFs are mostly synthesized from toluene diisocyanate and polyether polyols; hence, they have reactive groups of $-\mathrm{CH}_{2}-\mathrm{O}-\mathrm{CH}_{2}-$ and NHR$\mathrm{COO}-$ which can bond with Au complex anions during $\mathrm{Au}$ adsorption. In the process of $\mathrm{Au}$ digestion, a large amount of acid is used, and the solution is acidic; thus, $-\mathrm{CH}_{2}-\mathrm{O}-\mathrm{CH}_{2}-$ and NHR-COO- are prone to protonation and form positively charged organic cations. Since the Au complex anion, having stronger ionic potential and affinity than the simple anion, is easier to form an ionic association by electrostatic attraction with organic cation, so that $\mathrm{Au}$ is strongly enriched in the PUF. However, commercially available PUFs contain more impurities. If the PUFs are not treated, their effective adsorption area and capacity will be reduced, and some impurities will be easily eluted together with $\mathrm{Au}$ under the external force, resulting in a decrease of Au recovery. Therefore, the PUF must be properly treated before the experiment.

In addition, the soil samples need to be digested properly before the $\mathrm{Au}$ adsorption with PUFs. Common digestion methods include electric heating plate, water bath, high-pressure reactor, graphite and microwave digestion. This article compares the two methods of electric heating plate digestion in the national standard method and emerging microwave digestion. After the $\mathrm{Au}$ is completely enriched in the PUFs, the solution to be tested in ICP-MS should be obtained by the corresponding treatment of the PUFs. The general treatment methods are muffle furnace ashing-aqua regia dissolving $\mathrm{Au}$ and thiourea-hydrochloric acid desorbing $\mathrm{Au}$. In the former, the toxic gas is released when the PUFs are ashed, which harms the environment and human health. In the latter, the thiopeptide bond $(-\mathrm{CS}-\mathrm{NH}-)$ in thiourea is similar to the peptide bond $(-\mathrm{CO}-\mathrm{NH}-)$ in PUF. The large $\pi$ bond structure formed by the double bond and the lone electron pair of heteroatoms $(\mathrm{O}, \mathrm{N}, \mathrm{S})$ is the electron donor, and the $\mathrm{Au}$ ion is the electron acceptor. This structure may be helpful for the selective adsorption and desorption of $\mathrm{Au}$ ions and make them separate from most other interfering ions. At the same time, it is also necessary to select thiourea for gold desorption from the perspective of green chemistry.

This work aims to examine which pretreatment methods can better satisfy the precise and accurate $\mathrm{Au}$ determination in the soil through the research and comparison of PUF treatment, sample digestion, Au enrichment and desorption processes. It is also expected to establish a more perfect laboratory Au element analysis method with the advantages of simplicity, time saving, less sample usage, and environmental friendliness. 
Table 1 ICP-MS working parameters

\begin{tabular}{llll}
\hline Parameter & Setting & Parameter & Setting \\
\hline Radiofrequency power & $1150 \mathrm{~W}$ & Detector & Dual \\
Nebulizer gas flow & $0.92 \mathrm{~L} / \mathrm{min}$ & Measure mode & Standard \\
Cooling gas flow & $18 \mathrm{~L} / \mathrm{min}$ & Scanning mode & Peak hopping \\
Auxiliary gas flow & $1.2 \mathrm{~L} / \mathrm{min}$ & Dwell time & $50 \mathrm{~ms}$ \\
Sampling cone orifice & $1.1 \mathrm{~mm}$ & Sampling time & $60 \mathrm{~s}$ \\
Skimmer cone orifice & $0.9 \mathrm{~mm}$ & Sweep & 20 \\
Hyper skimmer cone orifice & $1.0 \mathrm{~mm}$ & Reading & 1 \\
Sampling depth & $8 \mathrm{~mm}$ & Number of replicates & 3 \\
\hline
\end{tabular}

\section{Materials and methods}

\section{Reagents and standards}

Hydrochloric acid $(\mathrm{HCl})$, nitric acid $\left(\mathrm{HNO}_{3}\right)$, and hydrofluoric acid (HF) in guaranteed reagent-grade and ultrapure deionized water with a resistivity of $18.2 \mathrm{M} \Omega \cdot \mathrm{cm}$ at $25{ }^{\circ} \mathrm{C}$ were used for sample preparation. The other reagents were of analytical grade. The main reagents prepared in the experiment were $250 \mathrm{~g} / \mathrm{L}$ ferric chloride $\left(\mathrm{FeCl}_{3}\right)$ solution (with $1 \% \mathrm{HCl}$ ), $10 \mathrm{~g} / \mathrm{L}$ thiourea solution (with $1 \% \mathrm{HCl}$ ), and aqua regia. The national standard Au single element solution (GSB 04-1715-2004, 1000 $\mu \mathrm{g} / \mathrm{mL}$ ) in $1.5 \mathrm{~mol} / \mathrm{L} \mathrm{HCl}$ was obtained from the $\mathrm{Na}$ tional Center of Analysis and Testing for Nonferrous Metals and Electronic Materials. The Au standard solutions required in the experiment were prepared by stepwise dilution. The Nexion setup solution containing Be, $\mathrm{Ce}, \mathrm{Fe}, \mathrm{In}, \mathrm{Li}, \mathrm{Mg}, \mathrm{Pb}$, and $\mathrm{U}(1 \mu \mathrm{g} / \mathrm{L})$ in $1 \% \mathrm{HNO}_{3}$ for ICP-MS condition optimization was purchased from PerkinElmer (USA). The purity of argon used in ICP-MS is higher than $99.999 \%$. Five certified reference materials (CRMs) of trace Au (GBW07805-6 and GBW07246-8) were acquired from the Institute of Geophysical and Geochemical Exploration, Chinese Academy of Geological Sciences (Langfang, China).

\section{Instrumentation}

Samples were weighed with an electronic balance (ATY124, Shimadzu, Japan) and ashed in a muffle furnace (SXL-1008, Jinghong, China). The electric heating plate (SB-1.8-4, Shanghai Shiyan, China), microwave digestion instrument (Titan MPS, PerkinElmer, USA), and graphite digestion instrument (SPB50-48, PerkinElmer, USA) were employed in the sample digestion process. The cyclotron oscillator (HY-8A, Jintan Jingda, China) and constant temperature water bath (HH-S26S, Jintan Instruments, China) devices were respectively used for $\mathrm{Au}$ enrichment and desorption. Au determination was performed on an ICP-MS (Nexion 350D, PerkinElmer, USA) instrument. The optimum ICP-MS operating conditions were summarized in Table 1.

\section{PUF treatment}

First, the PUF was cut into a small rectangular parallelepiped $\left(3 \times 2 \times 1 \mathrm{~cm}^{3}, 0.2 \mathrm{~g}\right)$, boiled for $30 \mathrm{~min}$ with $5 \%$ sodium hydroxide $(\mathrm{NaOH})$ solution, and washed with ultrapure deionized water until neutral. Then, it was immersed in $10 \% \mathrm{HCl}$ for $2 \mathrm{~h}$, rinsed to neutral, dried, and put in a clean plastic bottle for later use.

\section{Sample digestion}

Method I (electric heating plate digestion): With reference to the geological and mineral industry standard DZ/T0279.4-2016 of the People's Republic of China, combined with the actual situation of the laboratory, the experiment was designed as follows. Ten grams of sample was accurately weighed into a porcelain crucible, heated to $700{ }^{\circ} \mathrm{C}$ in a muffle furnace, and held for $1.5 \mathrm{~h}$. After cooling, the sample was transferred to a Teflon Erlenmeyer flask (TEF), into which $50 \mathrm{~mL} \mathrm{50 \%} \mathrm{aqua}$ regia was added. The TEF was placed on an electric heating plate and heated to dissolve the sample. The solution in TEF is kept slightly boiled, evaporated to half, and then cooled.

Method II (Microwave digestion): $0.25 \mathrm{~g}$ of the sample was accurately weighed into a Teflon reactor and wetted by a few drops of ultrapure deionized water. Ten milliliters of $50 \%$ aqua regia and $1 \mathrm{~mL}$ HF were sequentially added into the Teflon reactor. Then, the Teflon reactor was capped and placed in the microwave digestion apparatus. The sample digestion was carried out according to the heating program of Table 2. After the digestion was completed, the solution was transferred to a Teflon tube, heated to drive away the acid, and then cooled for use.

Table 2 Heating program of microwave digestion

\begin{tabular}{lllll}
\hline Step & $\mathbf{T} /{ }^{\circ} \mathbf{C}$ & $\mathbf{P} /$ bar & Ramp/min & Hold $/ \mathbf{m i n}$ \\
\hline 1 & 150 & 15 & 10 & 2 \\
2 & 190 & 20 & 5 & 2 \\
3 & 210 & 20 & 5 & 20 \\
4 & 50 & 20 & 0 & 10 \\
\hline
\end{tabular}


Table 3 The adsorption value and rate of Au standard solution by untreated and treated PUFS

\begin{tabular}{|c|c|c|c|c|c|c|}
\hline \multirow{2}{*}{$\begin{array}{l}\text { Standard } \\
\text { value } \\
\text { (ng/g) }\end{array}$} & \multicolumn{3}{|l|}{ Untreated PUF } & \multicolumn{3}{|l|}{ Treated PUF } \\
\hline & Adsorption value (ng/g) & RSD (\%) & Adsorption rate (\%) & Adsorption value $(\mathrm{ng} / \mathrm{g})$ & RSD (\%) & Adsorption rate (\%) \\
\hline 0.50 & 0.43 & 9.5 & 86.0 & 0.49 & 8.8 & 98.0 \\
\hline 1.00 & 0.84 & 6.8 & 84.0 & 0.97 & 9.0 & 97.0 \\
\hline 5.00 & 4.05 & 4.0 & 81.0 & 4.83 & 3.0 & 96.6 \\
\hline 10.00 & 7.92 & 0.6 & 79.2 & 9.57 & 2.0 & 95.7 \\
\hline 50.00 & 39.31 & 3.5 & 78.6 & 47.46 & 1.2 & 94.9 \\
\hline 100.00 & 77.14 & 1.9 & 77.1 & 92.58 & 1.5 & 92.6 \\
\hline
\end{tabular}

PUF polyurethane foam, $R S D$ relative standard deviation

\section{Au enrichment and desorption}

Eighty milliliters of ultrapure deionized water, $3 \mathrm{~mL}$ $\mathrm{FeCl}_{3}$ solution, and a PUF were added to the resulting solution of the TEF, which was then placed on a cyclotron, shaken for $30 \mathrm{~min}$ at a frequency of $200 \mathrm{rpm}$. Subsequently, the PUF was taken out from the flask, rinsed the residual acids and residues with ultrapure deionized water, drained the water with filter paper, and placed it in a $50-\mathrm{mL}$ colorimetric tube in which $25 \mathrm{~mL}$ thiourea solution had been added. After $45 \mathrm{~min}$ in the boiling water bath, the PUF was repeatedly pressed and taken out as soon as possible. The resulting solution was cooled to room temperature and to be measured.

At the same time, the same method was used for the blank control experiment.

\section{Results and discussion}

\section{Interference of coexisting ion}

The matrix elements of ferrosilicon, calcium, magnesium, potassium, and sodium in soil samples could not be adsorbed by the PUF. Although metal elements such as platinum, palladium, and rhodium would be adsorbed by the PUF, it did not affect the determination of $\mathrm{Au}$ content. Arsenic, sulfur, carbon, and organic matter could be effectively removed in the early high- temperature treatment and would not affect the measurement results.

\section{Comparison of Au enrichment ability of untreated and treated PUFs}

A series of Au standard solution $(0.50,1.00,5.00,10.00$, 50.00 , and $100.00 \mathrm{ng} / \mathrm{g}$ ) were separately adsorbed by untreated and treated PUFs, and the Au adsorption rate was calculated and compared in both cases to evaluate the adsorption effect. The specific experimental steps were as follows. Au standard solution and $25 \mathrm{~mL}$ aqua regia were added into a conical flask, shaken well, boiled, and then cooled. Subsequent experimental steps were the same as above "Au enrichment and desorption." The adsorption value and rate of Au standard solution by untreated and treated PUFs were listed in Table 3.

As can be seen from Table 3, the Au adsorption effect of treated PUF was better. With the increase of Au content, the Au adsorption rate of treated PUF decreased, and the average adsorption rate reached 95.8\%, which was significantly higher than the $81.0 \%$ of untreated PUF. Since the main impurities in the PUF were esters, the alkaline solution $(5 \% \mathrm{NaOH})$ had a good cleaning effect on them, which could increase the effective adsorption area of the PUF. Meanwhile, the PUF was socked in $10 \% \mathrm{HCl}$ for $2 \mathrm{~h}$ before using. Due to the acid effect, the

Table 4 Comparison of digestion processes between two pretreatment methods

\begin{tabular}{lll}
\hline Comparative content & Method I & Method II \\
\hline Weighing amount/g & 10.0000 & 0.2500 \\
Acid used & $50 \%$ aqua regia & $50 \%$ aqua regia + HF \\
Acid dosage/mL & 50 & $10+1=11$ \\
Digestion time/h & 8 & 2 \\
$\begin{array}{l}\text { The amount of samples } \\
\text { simultaneously digested }\end{array}$ & 40 & 8 \\
Sample digestion state & Light yellow brown liquid with some solid particles & Transparent liquid without solid particles \\
Labor consumption & Full manual supervision & Automated, unsupervised \\
Environmental and health & A lot of acid mist was generated to harm the respiratory & No acid mist, no significant impact on the \\
impact & tract, high temperature was easy to cause burns & environment and health \\
\hline
\end{tabular}


Table 5 The comparison of detection limit (DL) of five different methods

\begin{tabular}{lll}
\hline Analytical methods & DL (ng/g) & Reference \\
\hline ICP-MS after electric heating plate digestion, PUF enrichment, and thiourea desorption & 0.02 & This work \\
ICP-MS after microwave digestion, PUF enrichment, and thiourea desorption & 0.04 & This work \\
ICP-MS after microwave digestion, alkali fusion, and cation-exchange chromatography & 2.0 & Jarvis et al. 1997 \\
ICP-MS after NiS fire assay and Te co-precipitation & 0.053 & Oguri et al. 1999 \\
ICP-MS after extraction by an HCIO4-HBr-HI-aqua regia mixture & 2.0 & Strnad et al. 2016 \\
\hline
\end{tabular}

potential difference of the liquid membrane was increased, and the impurities such as calcium salt were better cleaned up, which further strengthened the $\mathrm{Au}$ adsorption rate. Therefore, the treatment method used for PUF can effectively improve its ability to adsorb Au.

\section{Comparison of two digestion methods}

Comparing the soil digestion process of the two pretreatment methods (Table 4), it was found that the electric heating plate digestion method was widely used, the required instrument was cheap and easily available, and more samples could be processed at the same time, but this method took a long time, consumed a large amount of mixed acid reagents and manpower, and the digestion was incomplete with partial insoluble silicate impurities remaining in the solution. Moreover, the electric heating plate digestion was an open digestion way with high temperature and a lot of acid mist generated to harm the environment and health, and the experimental process was susceptible to external interference and experimental operation level. The microwave digestion, a closed digestion method under high temperature and pressure, had the advantages of less sample and reagent dosage, shorter experiment time, high degree of automation, thorough digestion, safety, and environmental protection. Since the introduction of HF in the microwave digestion, the silicate in soil was dissolved, and the digestion solution obtained was transparent without solid particles. However, the instrument used was expensive, and the amount of samples simultaneously digested was smaller in the microwave digestion method.

\section{Validation of analytical methods}

The detection limits (DLs), estimated as three times the standard deviation of the blank, were $0.02 \mathrm{ng} / \mathrm{g}$ and 0.04 $\mathrm{ng} / \mathrm{g}$ for electric heating plate and microwave digestion methods, respectively. In Table 5, these two DLs by ICPMS were better than those using different digestion or enrichment procedures in early literatures (Jarvis et al. 1997; Oguri et al. 1999; Strnad et al. 2016). The accuracy and precision of the experimental method can be obtained by measuring the CRMs. Five CRMs (GBW07805-6 and GBW07246-8) with different Au content were separately analyzed 12 times under two digestion methods. The logarithmic deviation $(\Delta \operatorname{lgC})$, relative error $(\mathrm{RE})$, and relative standard deviation (RSD) values between the measured mean value and the standard value of each CRM were calculated and shown in Table 6. Because of the introduction of HF, the Au in the silicate was released, and the Au content of five CRMs obtained by microwave digestion is slightly higher than that by electric heating plate digestion in Table 6. According to the requirements of the geological and mineral industry standard DZ/T0011-2015 of the People's Republic of China, the two DLs were lower than those required by the standard $(0.3 \mathrm{ng} / \mathrm{g})$, the $\Delta \operatorname{lgC}$ and RE values of GBW07805-6 and GBW07246-8 were all smaller than the standard monitoring limits $(\Delta \lg C \leq 7 \%$ and $\mathrm{RE} \leq 50 \%$ ), and the RSDs were much less than $7 \%$ in

Table 6 The measurement result of Au element in five CRMs with two digestion methods

\begin{tabular}{|c|c|c|c|c|c|c|}
\hline CRM & Standard value $(\mathbf{n g} / \mathrm{g})$ & Method & Average value (ng/g) & $\Delta \operatorname{lgC}(\%)$ & RE (\%) & RSD (\%) \\
\hline \multirow[t]{2}{*}{ GBW07805 } & 0.85 & 1 & 0.82 & 1.6 & 3.5 & 6.2 \\
\hline & & $\|$ & 0.87 & 1.0 & 2.4 & 1.8 \\
\hline \multirow[t]{2}{*}{ GBW07806 } & 3.10 & 1 & 2.97 & 1.9 & 4.2 & 3.4 \\
\hline & & $\|$ & 3.29 & 2.6 & 6.1 & 1.7 \\
\hline \multirow[t]{2}{*}{ GBW07246 } & 20.80 & 1 & 21.72 & 1.9 & 4.4 & 5.1 \\
\hline & & $\|$ & 23.03 & 4.4 & 10.7 & 3.1 \\
\hline \multirow[t]{2}{*}{ GBW07247 } & 50.00 & 1 & 50.18 & 0.2 & 0.4 & 2.3 \\
\hline & & $\|$ & 53.89 & 3.3 & 7.8 & 1.3 \\
\hline \multirow[t]{2}{*}{ GBW07248 } & 100.00 & I & 105.50 & 2.3 & 5.5 & 0.7 \\
\hline & & $\|$ & 110.35 & 4.3 & 10.4 & 1.7 \\
\hline
\end{tabular}

I electric heating plate digestion method, I/ microwave digestion method, $\triangle \mathrm{g} C$ logarithmic deviation, RE relative error, RSD relative standard deviation 
Table 7 The measurement result of Au element in soil samples of actual Au mining area

\begin{tabular}{lllllll}
\hline Sample & Method & Average value $(\mathbf{n g} / \mathbf{g})$ & RSD (\%) & added amount $(\mathbf{n g} / \mathbf{g})$ & Measurement value (ng/g) & Recovery rate (\%) \\
\hline A1 & I & 180.47 & 1.8 & 200.00 & 373.02 & 96.3 \\
& II & 190.19 & 3.4 & 200.00 & 399.04 & 104.4 \\
A2 & I & 97.26 & 1.7 & 100.00 & 195.59 & 98.3 \\
& II & 103.64 & 2.1 & 100.00 & 200.97 & 97.3 \\
A3 & I & 74.21 & 1.3 & 100.00 & 175.88 & 101.7 \\
& II & 78.09 & 0.7 & 100.00 & 177.39 & 99.3 \\
B1 & I & 4.89 & 2.9 & 5.00 & 9.73 & 96.8 \\
& II & 5.20 & 2.3 & 5.00 & 10.08 & 97.6 \\
B2 & I & 2.45 & 1.2 & 2.00 & 4.36 & 95.5 \\
& II & 2.56 & 3.6 & 2.00 & 4.50 & 96.5 \\
B3 & I & 1.09 & 5.1 & 1.00 & 2.10 & 101.0 \\
\end{tabular}

I electric heating plate digestion method, // microwave digestion method, RSD relative standard deviation

Table 6 . These indicated that the accuracy and precision of the two experimental methods were high and satisfied the detection requirements.

\section{Application of pretreatment methods in soil samples of actual Au mining area}

In order to verify the reliability of different pretreatment methods, six soil samples were collected in the abnormal and background areas of an actual Au mine for testing, and the results are shown in Table 7. The parallel $(n=$ 6) and spiked recovery experiments were introduced, the RSDs (0.7-5.1\%) and recovery rates (95.5-104.4\%) in Table 7 proved the high precision and high accuracy of the experimental methods. As expected, the Au content of the soil in the abnormal area (A1-3) was much higher than that in the background area (B1-3). The variation of the Au content of the six samples measured by the two digestion methods was consistent, but the Au content obtained by microwave digestion is slightly higher than that by electric heating plate digestion due to the release of $\mathrm{Au}$ in silicate under the action of HF. The electric heating plate digestion method is a pretreatment method promoted in the geological and mineral industry standards DZ/T0279.4-2016 and DZ/T0279.19-2016, and the microwave digestion method can also satisfy the requirements of $\mathrm{Au}$ element analysis.

\section{Conclusion}

In this work, a series of comparison and improvement experiments for pretreatment methods were designed to ensure the accuracy and reliability of $\mathrm{Au}$ determination in soil via ICP-MS. The analysis results demonstrated that the reasonable treatment significantly improved the enrichment effect of PUF on Au. Both the electric heating plate and microwave digestion methods had low detection limits, high accuracy and precision, which could satisfy the requirements of analysis and detection. A little HF was added to release the Au in silicate during the microwave digestion, which improved the digestion effect and the measured value of $\mathrm{Au}$ in the soil samples. Compared with the electric heating plate digestion method in the geological and mineral industry standards, microwave digestion used a small amount of sample and reagents, took a short time, was carried out in a closed system without manual supervision, which could avoid the pollution and harm of the acid gas to the environment and human body, and was more in line with the development needs of green chemistry. In short, the microwave digestion-PUF enrichment-thiourea desorption-ICP-MS determination method has the potential as a routine laboratory method for the trace $\mathrm{Au}$ determination in various geological samples through the strict control of relevant conditional parameters.

\section{Abbreviations}

Au: Gold; ICP-MS: Inductively coupled plasma mass spectrometry; PUF: Polyurethane foam; $\mathrm{HCl}$ : Hydrochloric acid; $\mathrm{HNO}_{3}$ : Nitric acid; HF: Hydrofluoric acid; $\mathrm{FeCl}_{3}$ : Ferric chloride; CRMs: Certified reference materials; $\mathrm{NaOH}$ : Sodium hydroxide; TEF: Teflon Erlenmeyer flask; DLs: Detection limits; $\Delta \mathrm{lgC}$ : Logarithmic deviation; RE: Relative error; RSD: Relative standard deviation

\section{Acknowledgements}

Not applicable.

\section{Authors' contributions}

TXD, LJL, and LHY designed the experiment. TXD, LB, and ZYY carried out the experimental studies and collection, analysis, and interpretation of data. TXD wrote the manuscript. ZYY helped to draft and revise the manuscript. The authors read and approved the final manuscript.

\section{Funding}

This research was supported by the Chinese Academy of Geological Sciences Project (AS2016P02), Deep-penetrating Geochemistry Project (2016YFC0600606) funded by the State Key Research and Development Program. 


\section{Availability of data and materials}

The datasets supporting the conclusions of this article are included within the article.

\section{Competing interests}

The authors declare that they have no competing interests.

Received: 28 May 2020 Accepted: 6 October 2020

Published online: 15 October 2020

\section{References}

Afzali D, Mostafavi A, Mirzaei M. Preconcentration of gold ions from water samples by modified organo-nanoclay sorbent prior to flame atomic absorption spectrometry determination. J Hazard Mater. 2010;181(1):957-61.

Alim S, Vejayan J, Yusoff MM, Kafi AKM. Recent uses of carbon nanotubes \& gold nanoparticles in electrochemistry with application in biosensing: a review. Biosens Bioelectron. 2018;121:125-36.

Al-Merey R, Hariri Z, Abu HJ. Selective separation of gold from iron ore samples using ion exchange resin. Microchem J. 2003;75(3):169-77.

Balaram V, Vummiti D, Roy P, Taylor C, Kar P, Raju A, Abburi K. Determination of precious metals in rocks and ores by microwave plasma-atomic emission spectrometry for geochemical prospecting studies. Curr Sci. 2013;104(9): 1207-15.

Bashammakh AS, Bahaffi SO, Al-Shareef FM, El-Shahawi MS. Development of an analytical method for trace gold in aqueous solution using polyurethane foam sorbents: kinetic and thermodynamic characteristic of gold(III) sorption. Anal Sci. 2009;25(3):413-8.

Berezhnaya ED, Dubinin AV. Determination of the platinum-group elements and gold in ferromanganese nodule reference material NOD-A-1. Geochem Int. 2017;55(2):218-24.

Chen S, Yan J, Wang C, Lu D. Preconcentration and determination of $\mathrm{Au}(\mathrm{III})$, $\mathrm{Pd}(\mathrm{II})$, and $\mathrm{Pt}(\mathrm{IV})$ using dispersive micro-solid phase extraction with multiporous $\mathrm{ZnFe}_{2} \mathrm{O}_{4}$ nanotubes and ICP-MS. At Spectrosc. 2019;40(6):199-205.

Choi N-C, Kim B-J, Cho K, Lee S, Park C-Y. Microwave pretreatment for thiourea leaching for gold concentrate. Metals. 2017;7(10):404 .

Danscher G, Larsen A. Effects of dissolucytotic gold ions on recovering brain lesions. Histochem Cell Biol. 2010;133(4):367-73.

De La Calle I, Pena-Pereira F, Cabaleiro N, Lavilla I, Bendicho C. Ion pair-based dispersive liquid-liquid microextraction for gold determination at ppb level in solid samples after ultrasound-assisted extraction and in waters by electrothermal-atomic absorption spectrometry. Talanta. 2011;84(1):109-15.

George AZ, Konstantinos NA. The potential of desirability function strategy in chemometric optimization of ICP-AES for platinum group elements and gold. Curr Anal Chem. 2016;12(2):147-58.

Guo W, Xie W, Jin L, Guo Q, Hu S. Determination of sub-ng g - 1 Au in geological samples by ion molecule reaction ICP-MS and $\mathrm{CH} 4$ plasma modifier. RSC Adv. 2015;5(125):103189-94.

Hassan J, Shamsipur M, Karbasi M-H. Single granular activated carbon microextraction and graphite furnace atomic absorption spectrometry determination for trace amount of gold in aqueous and geological samples. Microchem J. 2011;99(1):93-6

Hassan J, Zari N, Tabar-Heydar K, Ahmadi SH. Ion-association dispersive liquidliquid microextraction of ultra-trace amount of gold in water samples using Aliquat 336 prior to inductively coupled plasma atomic emission spectrometry determination. J Anal Sci Technol. 2016;7(1):22.

Ilankoon ND, Aldrich C, Oraby EA, Eksteen JJ. Use of polyethylenimine functionalised magnetic nanoparticles for gold thiosulfate recovery. Hydrometallurgy. 2020;195:105375.

Itagaki T, Ashino T, Takada K. Determination of trace amounts of gold and silver in high-purity iron and steel by electrothermal atomic absorption spectrometry after reductive coprecipitation. Fresenius J Anal Chem. 2000; 368(4):344-9.

Jarvis I, Totland MM, Jarvis KE. Assessment of Dowex 1-X8-based anion-exchange procedures for the separation and determination of ruthenium, rhodium, palladium, iridium, platinum and gold in geological samples by inductively coupled plasma mass spectrometry. Analyst. 1997;122(1):19-26.

Liang P, Zhao E, Ding Q, Du D. Multiwalled carbon nanotubes microcolumn preconcentration and determination of gold in geological and water samples by flame atomic absorption spectrometry. Spectrochim Acta B. 2008; 63(6):714-7.
Liu J, Zou D, Yang X, Cheng X, Chen Q. A modified persimmon powder sorbent for selective separation and determination of trace gold in geological samples by ICP-MS. Anal Methods-UK. 2013;5(23):6774-80.

Maduraiveeran G, Ramaraj R. Gold nanoparticle-based sensing platform of hydrazine, sulfite, and nitrite for food safety and environmental monitoring. J Anal Sci Technol. 2017;8(1):14.

Noel JG. Review of the properties of gold material for MEMS membrane applications. IET Circ Device Syst. 2016;10(2):156-61.

Oguri K, Shimoda G, Tatsumi Y. Quantitative determination of gold and the platinum-group elements in geological samples using improved NiS fireassay and tellurium coprecipitation with inductively coupled plasma-mass spectrometry (ICP-MS). Chem Geol. 1999;157(3):189-97.

Oya AU, Zeynep YG, Sabahattin D, Ece KY, Adnan A. A novel ligand for cloud point extraction to determine gold content in ore samples. Environ Chem Lett. 2014;12(3):449-53.

Pyrzynska K. Sorbent materials for separation and preconcentration of gold in environmental and geological samples - a review. Anal Chim Acta. 2012;741:9-14.

Qi L, Gao J, Huang X, Hu J, Zhou M-F, Zhong H. An improved digestion technique for determination of platinum group elements in geological samples. J Anal Atom Spectrom. 2011;26(9):1900-4.

Qu R, Sun C, Wang M, Ji C, Xu Q, Zhang Y, Wang C, Chen H, Yin P. Adsorption of $\mathrm{Au}(\mathrm{III})$ from aqueous solution using cotton fiber/chitosan composite adsorbents. Hydrometallurgy. 2009;100(1):65-71.

Qu R, Wang M, Sun C, Zhang Y, Ji C, Chen H, Meng Y, Yin P. Chemical modification of silica-gel with hydroxyl- or amino-terminated polyamine for adsorption of Au(III). Appl Surf Sci. 2008;255(5, Part 2):3361-70.

Resano M, McIntosh KS, Vanhaecke F. Laser ablation-inductively coupled plasmamass spectrometry using a double-focusing sector field mass spectrometer of Mattauch-Herzog geometry and an array detector for the determination of platinum group metals and gold in NiS buttons obtained by fire assay of platiniferous ores. J Anal Atom Spectrom. 2012;27(1):165-73.

Sabermahani F, Taher MA, Bahrami H. Separation and preconcentration of trace amounts of gold from water samples prior to determination by flame atomic absorption spectrometry. Arab J Chem. 2016;9:S1700-5.

Satyanarayanan M, Balaram V, Sawan SS, Subramanyam K, Krishna G, Dasaram B, Manikyamba C. Rapid determination of REEs, PGEs, and other trace elements in geological and environmental materials by high resolution inductively coupled plasma mass spectrometry. At Spectrosc. 2018;39(1):1-15.

Sheoran V, Sheoran AS, Poonia P. Phytomining of gold: a review. J Geochem Explor. 2013;128:42-50.

Stefano C, Silvano B, Lorenzo R, Simone B, Massimo I, Giovanni P. Simultaneous determination of gold and palladium via potentiometric titration. Curr Anal Chem. 2015;11(3):217-24.

Strnad L, Šebek O, Fayadová M, Vrba J. Determination of Gold in e-Waste dust samples and geological matrices by ICP-MS after extraction by an $\mathrm{HClO} 4$ HBr-HI-Aqua regia mixture. Geostand Geoanal Res. 2016;40(2):257-66.

Tang X, Li H, Liu H, Li B, Zhao Y, Lu J, Zhou J, Liu Q. Comparative study on two pretreatment processes for chemical phase analysis of gold in geological samples by atomic absorption spectrometry. J Anal Methods Chem. 2019. https://doi.org/10.1155/2019/1792792.

Tao D, Guo W, Xie W, Jin L, Guo Q, Hu S. Rapid and accurate determination of gold in geological materials by an improved ICP-MS method. Microchem J. 2017;135:221-5.

Tu Z, Lu S, Chang X, Li Z, Hu Z, Zhang L, Tian H. Selective solid-phase extraction and separation of trace gold, palladium and platinum using activated carbon modified with ethyl-3-(2-aminoethylamino)-2-chlorobut-2-enoate. Microchim Acta. 2011;173(1):231-9.

Wang C, Wang D, Xu J, Ying L, Liu L, Liu S. A preliminary review of metallogenic regularity of gold deposits in China. Acta Geol Sin-Engl. 2015;89(2):632-51.

Wang Y, Brindle ID. Rapid high-performance sample digestion for ICP determination by ColdBlock ${ }^{\text {TM }}$ digestion: part 2: gold determination in geological samples with memory effect elimination. J Anal Atom Spectrom. 2014;29(10):1904-11.

Xu B, Li K, Li Q, Yang Y, Liu X, Jiang T. Kinetic studies of gold leaching from a gold concentrate calcine by thiosulfate with cobalt-ammonia catalysis and gold recovery by resin adsorption from its pregnant solution. Sep Purif Technol. 2019;213:368-77.

Xue D, Wang H, Liu Y, Shen P, Sun J. Cytosine-functionalized polyurethane foam and its use as a sorbent for the determination of gold in geological samples. Anal Methods-UK. 2016;8(1):29-39. 
Yang W, Hashmi ASK. Mechanistic insights into the gold chemistry of allenes. Chem Soc Rev. 2014:43(9):2941-55.

Yeo C, Ooi K, Tiekink E. Gold-based medicine: a paradigm shift in anti-cancer therapy? Molecules. 2018;23(6):1410.

Yilmaz E, Soylak M. Supramolecular solvent microextraction of gold prior to its determination by microsample injection system coupled with flame atomic absorption spectrometry. RSC Adv. 2014;4(88):47396-401.

Yim SA, Choi MS, Chae JS. Direct determination of gold in rock samples using collision cell quadrupole ICP-MS. J Am Soc Mass Spectrom. 2012;23(1):171-8.

Zhou S, Song N, Lv X, Jia Q. Magnetic dual task-specific polymeric ionic liquid nanoparticles for preconcentration and determination of gold, palladium and platinum prior to their quantitation by graphite furnace AAS. Microchim Acta. 2017;184(9):3497-504.

\section{Publisher's Note}

Springer Nature remains neutral with regard to jurisdictional claims in published maps and institutional affiliations.

\section{Submit your manuscript to a SpringerOpen ${ }^{\circ}$ journal and benefit from:}

- Convenient online submission

- Rigorous peer review

- Open access: articles freely available online

- High visibility within the field

- Retaining the copyright to your article

Submit your next manuscript at $\boldsymbol{\nabla}$ springeropen.com 